\title{
EXPERIMENTAL TESTS ON A HYBRID TIMBER-FRAME WALL SYSTEM
}

\author{
M. IZZI ${ }^{1,2}$, D. CASAGRANDE ${ }^{1}$, E. SINITO ${ }^{1,3}$, G. PASETTO $^{1} \&$ A. POLASTRI $^{1}$ \\ ${ }^{1}$ CNR-IVALSA, Via Biasi, San Michele all'Adige, Italy. \\ ${ }^{2}$ University of Trieste, Piazzale Europa, Trieste, Italy. \\ ${ }^{3} \mathrm{X}$-Lam Dolomiti, Via della Stazione, Castel Ivano, Italy.
}

\begin{abstract}
This paper presents an innovative lateral load-resisting wall system, which is an evolution of the lighttimber frame (LTF) shear walls currently available on the market. In comparison to traditional LTF walls, the novelty aspect is the use of cross-laminated timber (CLT) beams and studs instead of solid timber elements. Thanks to this 'hybrid' approach, this new system combines some peculiar aspects of LTF structures (such as the limited weight and the high dissipative behaviour) with the potentials of CLT. Moreover, the use of CLT elements limits the issues due to the compressive deformations on bottom beams and permits to employ some innovative connections with high mechanical properties. Cyclic shear tests are carried out on two configurations of interest, assembled by considering different layouts of the load-bearing elements. Test results are compared to the experimental data obtained on similar LTF systems and differences are critically discussed.
\end{abstract}

Keywords: Cross-Laminated Timber, cyclic shear test, emergency housing facilities, hybrid structures, Light-framed wall system, seismic behaviour

\section{INTRODUCTION}

In recent years, the seismic behaviour of light-framed (LTF) and massive timber structures (assembled, e.g., using cross-laminated timber panels, CLT) has been the focus of several research projects. Extensive experimental programmes investigated the hysteretic behaviour of typical LTF and CLT lateral load-resisting systems (the so-called 'wall systems', i.e. walls with connections) and full-scale buildings, demonstrating satisfactory performances under seismic conditions (see, for example, Refs. [1-14]). Based on the experimental data acquired from previous test programmes, the following conclusions can be withdrawn:

- LTF construction system

$\checkmark$ Suitable to erect low- and mid-rise buildings (three- to six-storey high)

$\checkmark$ Wall systems have limited weight, thanks to an efficient use of timber

$\checkmark$ Capable to ensure large ductility ratios and a high dissipative behaviour

$\boldsymbol{x}$ Possible issues with the compressive deformations on bottom beams

$x$ Possible shear failures of the sheathing panels near to the bottom corners

- CLT construction system

$\checkmark$ Suitable to erect mid- and high-rise buildings (more than six-storey high)

$\checkmark$ Wall systems with high mechanical properties (stiffness and maximum load)

$\checkmark$ Segmented wall systems capable to ensure a good dissipative behaviour

$\boldsymbol{x}$ Energy dissipation localized into few mechanical connections

$x$ Relevant erection costs, due to the significant amount of timber required

To overcome the limitations of LTF shear walls, this contribution presents an innovative wall system where some peculiar aspects of LTF structures (such as the low weight and the high dissipative behaviour) are combined with the potentials of CLT. In fact, in comparison with 
traditional LTF walls, the novelty aspect is the use of CLT beams and studs instead of solid timber elements. Thanks to this 'hybrid' approach, this new system (in the following referred to as Hybrid Timber-Frame, HTF) leads to the following advantages:

$\checkmark$ Prevents the issues due to the compressive deformations on bottom beams

$\checkmark$ Permits to adopt some innovative connections with high mechanical properties

$\checkmark$ Increases the energy dissipation, maintaining adequate mechanical properties

$\checkmark$ Allows the erection of multi-storey structures with a limited amount of timber

Preliminary cyclic shear tests on the HTF wall system are carried out in the framework of the TRE3 research project on two configurations of interest, assembled by considering different layouts of the load-bearing elements. The experimental results are compared to the test data obtained on similar LTF walls and differences are critically discussed.

\section{THE 'HYBRID TIMBER-FRAME' WALL SYSTEM}

The hybrid timber-frame (HTF) wall system is an innovative light-framed wall where the timber members (top and bottom beams, as well as inner and outer studs) are made of CLT while traditional wood-panels (e.g. OSB or plywood) are used as sheathing elements on one or both sides of the frame.

The benefits of using CLT elements in a timber-framed wall are remarkable. Firstly, the strength of the bottom beam subjected to the axial loads of the studs is significantly increased, since the vertical lamellas limit the compressive deformations perpendicular to the grain. Secondly, the CLT elements permit to adopt prefabricated connections with high mechanical properties (e.g. the X-RAD system [15]), which resist in the same plane of the wall; therefore, failure mechanisms either due to an eccentricity between the wall and the connections [4] or to an intersection of the sheathing panel between the anchoring device and the outer stud [10] are prevented. In addition, the use of prefabricated connections ensures both a rapid on-site assembling and a complete dismantling. Finally, replacing solid wood members with CLT elements represents a sustainable solution, since those elements can be obtained as residual parts from the cutting process of CLT panels (e.g. from doors and windows openings).

The mechanical behaviour of a HTF wall subjected to an in-plane lateral load is described by taking as a reference a traditional LTF system. The wood-based sheathing panels, connected to the CLT frame with metal fasteners (e.g. profiled nails), ensure the in-plane stability of the wall. However, differently from LTF walls, hold-down and shear connections are replaced with prefabricated and high-performing connections, which are located in correspondence to the bottom corners of the wall and avoid the rigid body rotation and the slippage.

The transmission of shear stresses between the sheathing panels and the structural frame can be studied by means of either elastic or plastic mechanical models, while simplified analytical procedures are commonly adopted by the practitioners. Generally, the calculation models employ the lower bound theorem limit analysis and the following simplifications: the dowel-type fasteners behave in a rigid-plastic manner, the sheathing panel is subjected to a constant shear stress distribution, and the outer studs are directly connected to the foundation.

According to the calculation model prescribed in Eurocode 5 [16], the racking load-carrying capacity of each sheathing panel $F_{\mathrm{w}, \mathrm{Rd}, \mathrm{i}}$ is calculated as: 


$$
F_{\mathrm{w}, \mathrm{Rd}, \mathrm{i}}=\frac{F_{\mathrm{f}, \mathrm{Rd}}}{s} b_{\mathrm{i}} c_{\mathrm{i}},
$$

where $F_{\mathrm{f}, \mathrm{Rd}}$ is the lateral design capacity of an individual fastener, $b_{\mathrm{i}}$ is the panel width, $s$ is the fastener spacing and $c_{\mathrm{i}}$ is a correction factor, which takes into account the geometrical distribution of the fasteners along the panel edges. If the height of the panel is denoted with the symbol $h$, the factor $c_{\mathrm{i}}$ can assume the following values:

$$
c_{\mathrm{i}}=\left\{\begin{array}{cc}
0 & b_{\mathrm{i}}<h / 4 \\
2 \frac{b_{\mathrm{i}}}{h} & h / 4<b_{\mathrm{i}}<h / 2 \\
1 & b_{\mathrm{i}} \geq h / 2
\end{array}\right.
$$

When more than one sheathing-panel is adopted, the racking load-carrying capacity of the entire wall $\left(F_{\mathrm{w}, \mathrm{Rd}}\right)$ is calculated as shown in Equation 3, where $n_{\mathrm{bs}}$ is the number of braced sides of the wall (equal to 1 when only one side is braced and equal to 2 otherwise).

$$
F_{\mathrm{w}, \mathrm{Rd}}=n_{\mathrm{bs}} \frac{F_{\mathrm{f}, \mathrm{Rd}}}{s} \sum_{i} b_{\mathrm{i}} c_{\mathrm{i}}
$$

If the sheathing panels have the same width, Equation 3 can be rewritten as a function of the total width of the wall $B$, leading to:

$$
F_{\mathrm{w}, \mathrm{Rd}}=n_{\mathrm{bs}} \frac{F_{\mathrm{f}, \mathrm{Rd}}}{s} B c .
$$

Hence, the design verification of the racking load-carrying capacity of the wall is performed as shown in Equation 5, with $F_{\mathrm{Ed}}$ the design value of the shear force applied to the wall.

$$
F_{\text {w,Rd }} \geq F_{\text {Ed }} \text {. }
$$

The horizontal $(x)$ and vertical $(y)$ components acting on each anchoring device (denoted as $T_{\mathrm{a}, \mathrm{Ed}, \mathrm{x}}$ and $T_{\mathrm{a}, \mathrm{Ed}, \mathrm{y}}$ ) are calculated using the methods of mechanics, considering the overturning moment $M_{\mathrm{Ed}}$, the shear force $F_{\mathrm{Ed}}$ and the distributed load $q_{\mathrm{Ed}}$ applied on top of the frame. When the over-turning moment is higher than the stabilizing moment due to the vertical load $\left(M_{\mathrm{q}}=0.5 q_{\mathrm{Ed}} B^{2}\right)$, the $y$-component of the tensile $\left(T_{\mathrm{a}, \mathrm{Ed}, \mathrm{y}, \mathrm{t}}\right)$ and compressed $\left(T_{\mathrm{a}, \mathrm{Ed}, \mathrm{y}, \mathrm{c}}\right)$ corners of the wall are calculated based on Equation 6 and 7, respectively.

$$
\begin{gathered}
T_{\mathrm{a}, \mathrm{Ed}, \mathrm{y}, \mathrm{t}}=\frac{M_{\mathrm{Ed}}}{0.95 B}-\frac{q_{\mathrm{Ed}} B}{2} \geq 0 \\
T_{\mathrm{a}, \mathrm{Ed}, \mathrm{y}, \mathrm{c}}=\frac{M_{\mathrm{Ed}}}{0.95 B}+\frac{q_{\mathrm{Ed}} B}{2}
\end{gathered}
$$

When $M_{\mathrm{Ed}}<M_{\mathrm{q}}$, the rigid rotation of the wall is prevented by effect of the vertical load and $T_{\mathrm{a}, \mathrm{Ed}, \mathrm{y}}=0$. The horizontal component acting on each connection is determined according to Equation 8, assuming the same shear stiffness of each connector.

$$
T_{\mathrm{a}, \mathrm{Ed}, \mathrm{x}}=0.5 F_{\mathrm{Ed}}
$$

The static verification of the connections is carried out by taking into account the failure mechanisms related to both the steel components and the steel-to-timber joints. However, 
further analyses are required to identify the load distribution on the connections that are used in a HTF system, taking into account all geometrical and mechanical wall configurations. In this context, it should be noticed that the use of innovative connections with high mechanical properties [17, 18], instead of traditional hold-downs and angle brackets leads to several advantages in terms of seismic capacity of the wall system. As discussed by Casagrande et al. [19] and Follesa et al. [20], the dissipative zones of timber-framed structures should be concentrated into the sheathing-to-framing connections. On the contrary, anchoring devices should behave elastically and designed in accordance with the capacity design approach. Furthermore, connections with high stiffness values reduce the lateral deformation of the wall and increase its ductility [21].

In this paper, two possible configurations of a HTF wall are presented and analysed by means of preliminary cyclic shear tests. In the first configurations, (HTF-1, Fig. 1a), the anchoring devices are restrained to the bottom beam. For this reason, a large CLT element is necessary to install the anchoring devices and to ensure the structural stability. The inner studs and the top beam are designed in accordance with the vertical load verification, while the outer studs are designed by taking into account the horizontal load applied to the wall. On the other hand, in the second configuration (HTF-2, Fig. 1b) the connections are restrained to the outer studs, which are made with large CLT elements. Top and bottom beams, as well as the inner studs, are made with small CLT elements and their geometrical dimensions are determined according to the static verification of the vertical loads.
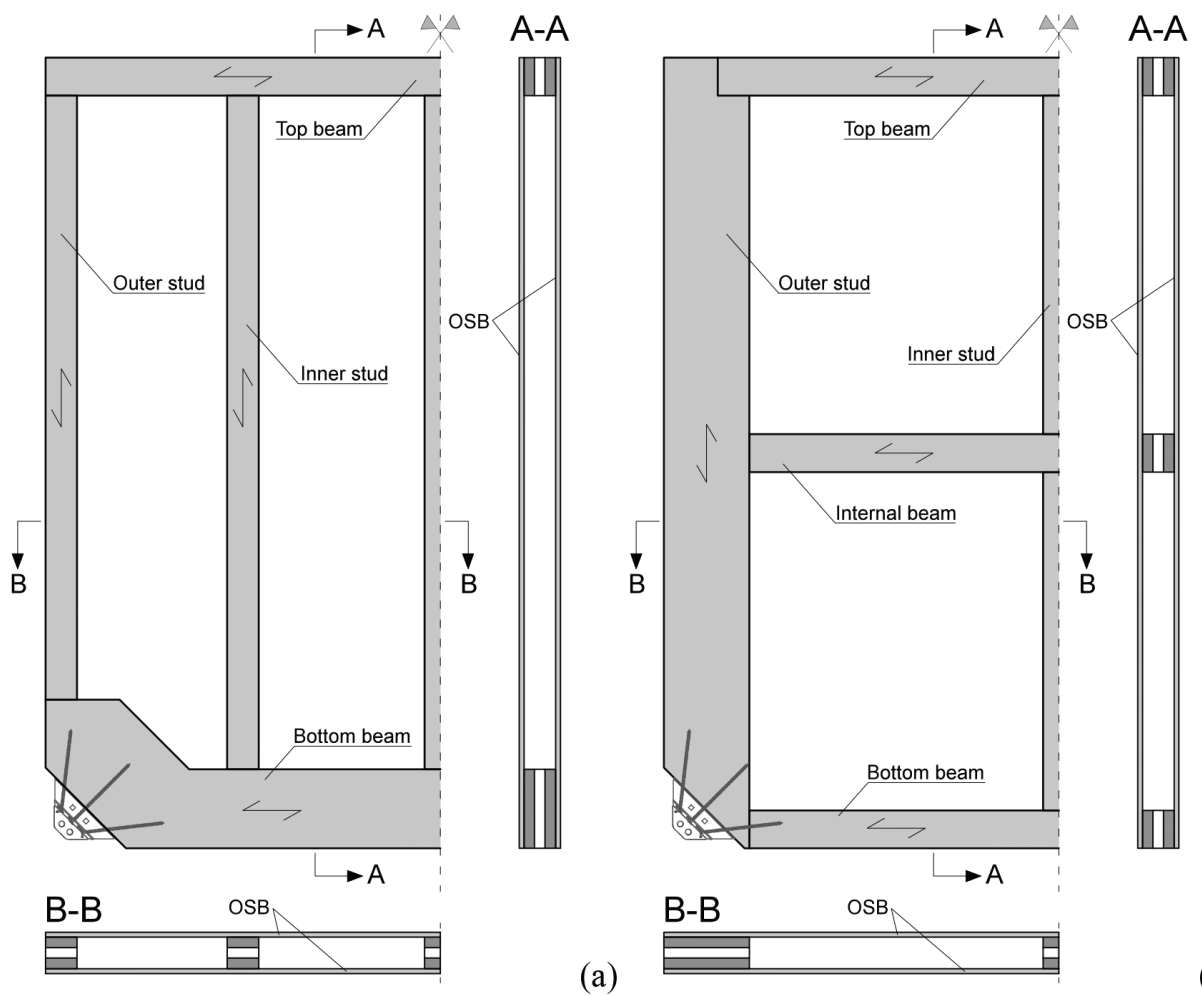

(b)

Figure 1: Schematics of the HTF walls considered in this study: (a) HTF-1 and (b) HTF-2. 
In the HTF-1 configuration, the stresses due to the rocking of the wall are directly transmitted from the sheathing panel to the anchoring devices via the bottom beam. As a result, the typical models for LTF walls cannot be used since a not-uniform stress distribution of the fasteners along the edge of the sheathing panel is expected. The HTF-2 configuration allows a direct transmission of tensile loads from the outer studs to the foundation. For this reason, the wall can be designed by employing similar mechanical models to those used for typical LTF walls (where hold-downs are used).

Despite the fact that the HTF system is a special case of the LTF structural typology, specific mechanical models should be developed to obtain reliable predictions of the loadcarrying capacity. In particular, since different configurations of the load-bearing elements can be adopted and innovative connections are used, a direct employment of LTF models could be not suitable. Based on this, analytical, numerical, and experimental analyses are ongoing to investigate the mechanical behaviour of this new structural system.

\section{EMERGENCY HOUSING FACILITIES}

In recent years, due to the occurrence of catastrophic natural disasters (e.g. earthquakes and hurricanes) and the increasing number of refugees, emergency housing facilities have gained significant importance in the field of building constructions. According to the guidelines that were released by the Italian Department of Civil Protection after the 2002 Molise earthquake $[22,23]$, the emergency phases are usually dealt in two steps. The first step takes place right after the disaster; tent cities are erected to satisfy the primary needs of the population and to guarantee a safe shelter. The second step begins few months after the disaster and lasts two or three years. In this time, tents are replaced by housing units. In conjunction with this step, the renovation of damaged buildings takes place.

Nowadays, emergency housing units consist of prefabricated 3D systems, which suffer from transport and handling limitations. To overcome such issues, the TRE3 research project aims at proposing an innovative $2 \mathrm{D}$ wall module that is a first applicative example of the HTF wall presented in the previous section. Three basic modules were identified (Fig. 2), which can be used to assemble several types of emergency units (Fig. 3).

\section{EXPERIMENTAL TESTS AND DISCUSSION}

Cyclic shear tests were carried out on the HTF wall systems presented in Section 2; tests were performed on $2500 \times 2500 \mathrm{~mm}$ specimens assembled using $100 \mathrm{~mm}$ thick CLT panels (three
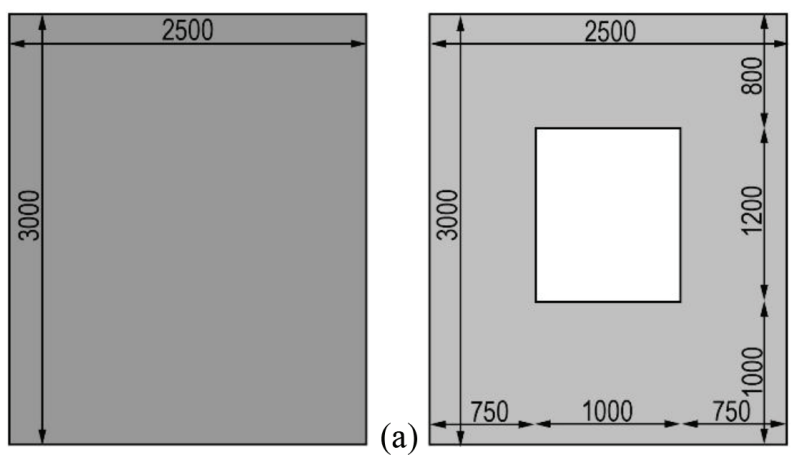

(b)

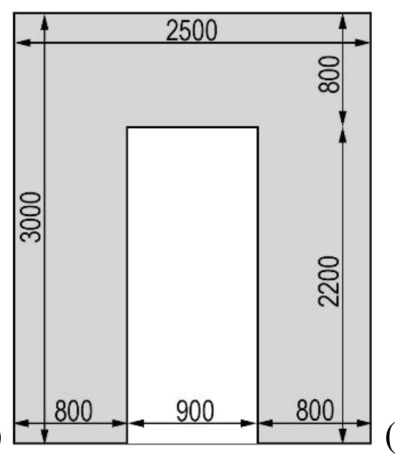

(c)

Figure 2: Schematics of the wall modules developed within the TRE3 research project. 


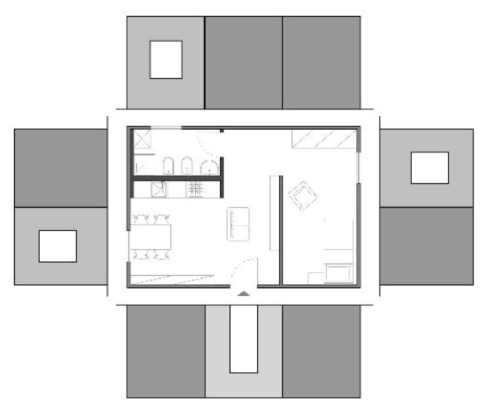

(a)

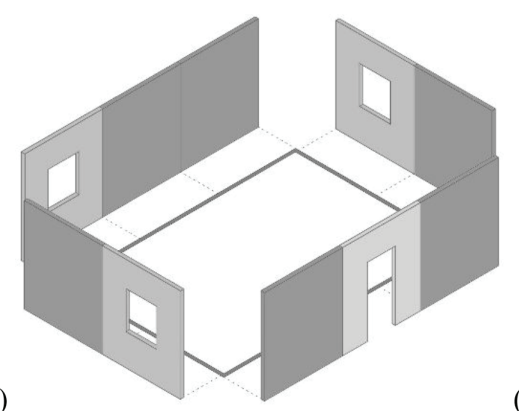

(b)

Figure 3: Planar and 3D views of a housing unit assembled with the TRE3 modules.

board layers) provided by X-Lam Dolomiti [24] and Rothoblaas X-RAD connections [15]. The CLT frame of each test specimen was assembled as follows (see Fig. 1):

- HTF-1

- One top beam $(120 \mathrm{~mm} \times 2500 \mathrm{~mm})$

- One bottom beam $(500 \mathrm{~mm} \times 2500 \mathrm{~mm})$

- Two outer studs $(100 \mathrm{~mm} \times 1910 \mathrm{~mm})$

- Three inner studs $(100 \mathrm{~mm} \times 2130 \mathrm{~mm})$

- HTF-2

- One top beam $(120 \mathrm{~mm} \times 2160 \mathrm{~mm})$

- One internal beam $(120 \mathrm{~mm} \times 1960 \mathrm{~mm})$

- One bottom beam $(120 \mathrm{~mm} \times 1960 \mathrm{~mm})$

- Two outer studs $(270 \mathrm{~mm} \times 2500 \mathrm{~mm})$

- Two inner studs $(100 \mathrm{~mm} \times 1070 \mathrm{~mm})$

The test specimens were braced on both sides with $15 \mathrm{~mm}$ thick OSB panels, fastened to the timber frame with $3.1 \mathrm{~mm}$ thick and $80 \mathrm{~mm}$ long annular-ringed shank nails. The nails were spaced $100 \mathrm{~mm}$ along the OSB edges. In both cases, to ensure a direct transmission of the shear stresses from the OSB sheathing to the CLT frame, no fasteners were used to connect the inner and the outer studs to the top and bottom beams. Tests were carried out according to the EN 12512:2001/A1 [25], assuming an yield displacement of $10 \mathrm{~mm}$; furthermore, no vertical load was applied on top of the walls. The experimental test data were post-processed following a procedure described in Izzi et al. [26].

Figures 4 and 5 display the experimental hysteresis and the history of dissipated energy of the HTF-1 (Fig. 4) and HTF-2 (Fig. 5) wall, respectively. The test data were compared with similar results obtained on a typical LTF wall, published by Grossi et al. [9].

Figure 6 shows a comparison among the first envelope curves extracted from the test data of the LTF, HTF-1 and HTF-2 wall systems, while Table 1 lists the maximum loads attained on the first $\left(F_{\max (1 \mathrm{st})}\right)$ and third $\left(F_{\max (3 \mathrm{rd})}\right)$ envelope curves and the impairment of strength, which was defined as $\Delta F=\left(F_{\max (1 \mathrm{st})}-F_{\max (3 \mathrm{rd})}\right) / F_{\max (1 \mathrm{st})} \cdot 100$.

The HTF-1 specimen showed a significant reduction of strength and stiffness in comparison with the traditional LTF wall. As expected, the failure was attained in the nails located on the bottom edges of the sheathing panels. Since there was no direct anchoring of the outer studs to the foundation, the mechanical behaviour of the nails embedded in the bottom beam was significantly influenced by the wall rocking contribution (Fig. 7). 


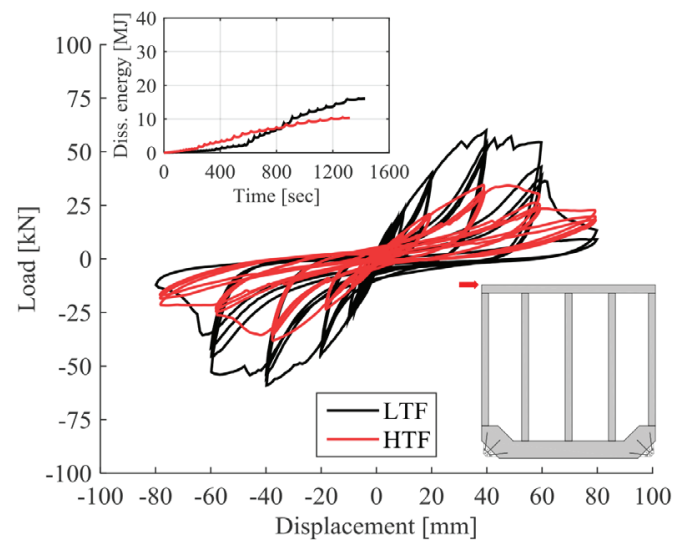

Figure 4: Preliminary test results on the HTF-1 wall configuration.

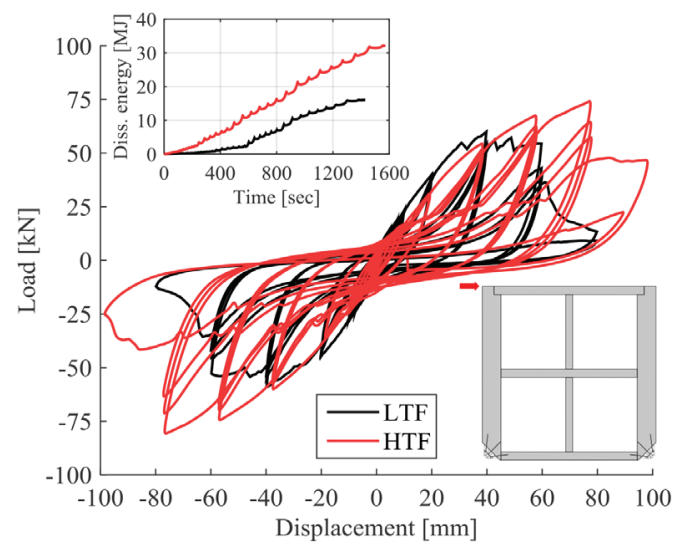

Figure 5: Preliminary test results on the HTF-2 wall configuration.

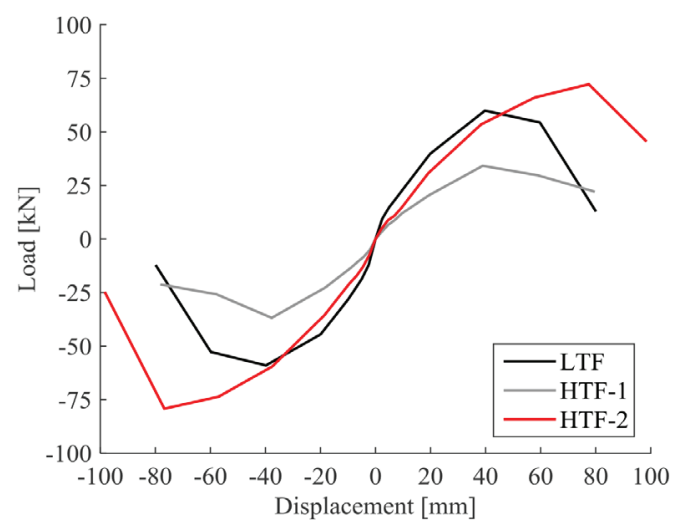

Figure 6: Comparison among the first envelope curves extracted from the test data. 
Table 1: Maximum load measured on the first and third envelope curve.

\begin{tabular}{llll}
\hline & \multicolumn{2}{l}{ Wall system } & \\
\cline { 2 - 4 } Mechanical properties & LTF & HTF-1 & HTF-2 \\
\hline$F_{\max (1 \mathrm{st})}[\mathrm{kN}]$ & 59.92 & 34.50 & 74.14 \\
$F_{\max (3 \mathrm{rd})}[\mathrm{kN}]$ & 51.68 & 30.62 & 59.96 \\
$\Delta F[\%]$ & 13.75 & 11.25 & 19.12 \\
\hline
\end{tabular}
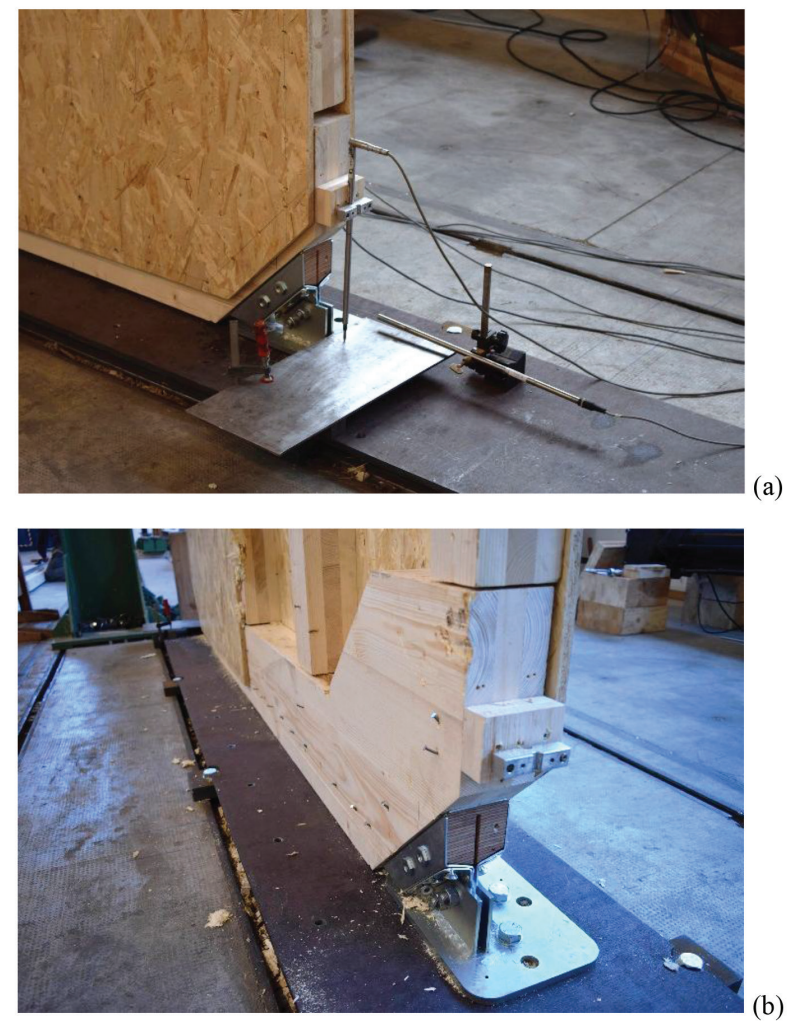

Figure 7: Details of the HTF-1 wall specimen.

The HTF-2 specimen showed a greater mechanical behaviour compared to both the LTF and the HTF-1 specimens. In similarity with the previous case, the failure was attained in the nails located along the edges of the OSB panels, while damages were not observed neither in the anchoring devices nor in the OSB panels (Fig. 8). Despite the use of X-RAD systems, no significant increment of stiffness was observed in comparison with the LTF specimen, where a traditional hold-down was used.

Finally, Table 2 shows the equivalent viscous damping ratios of the three wall systems taken as a reference in this study, evaluated on the first $\left(v_{\text {eq(1st) }}\right)$ and third $\left(v_{\text {eq(3rd })}\right)$ hysteresis loops. The specimens lead to similar equivalent viscous damping ratios on the first hysteresis 

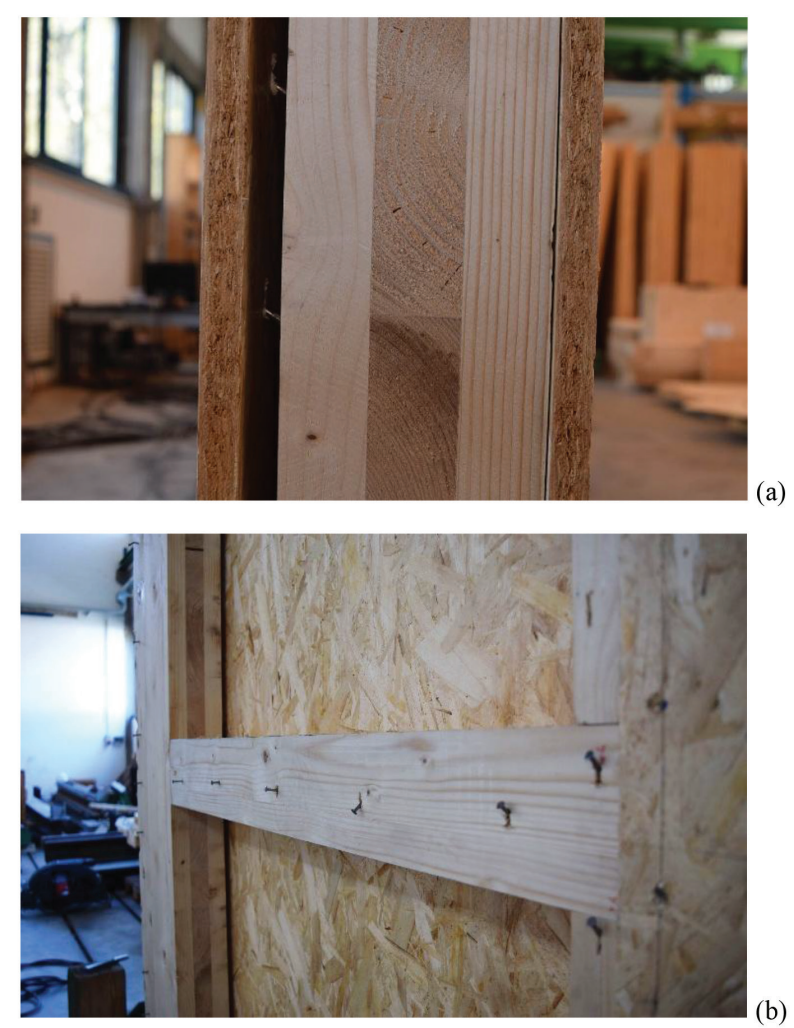

Figure 8: Details of the HTF-2 wall specimen.

Table 2: Equivalent viscous damping ratios at different displacement amplitudes, evaluated on the first $\left(v_{\text {eq(1st })}\right)$ and third $\left(v_{\text {eq(3rd })}\right)$ hysteresis loops.

\begin{tabular}{|c|c|c|c|c|}
\hline \multirow[b]{2}{*}{ Amplitude } & & \multicolumn{3}{|c|}{ Wall system } \\
\hline & & LTF & HTF-1 & HTF-2 \\
\hline \multirow[t]{2}{*}{$0.75 \cdot V_{\mathrm{y}}$} & $v_{\mathrm{eq}(1 \mathrm{st})}[\%]$ & 13.28 & 13.92 & 19.79 \\
\hline & $v_{\text {eq(3rd })}[\%]$ & 10.22 & 10.85 & 19.74 \\
\hline \multirow[t]{2}{*}{$V_{\mathrm{y}}$} & $v_{\mathrm{eq}(1 \mathrm{st})}[\%]$ & 11.14 & 11.36 & 18.38 \\
\hline & $v_{\text {eq(3rd) }}[\%]$ & 8.95 & 9.87 & 17.82 \\
\hline \multirow[t]{2}{*}{$2 \cdot V_{\mathrm{y}}$} & $v_{\text {eq(1st })}[\%]$ & 13.21 & 13.08 & 14.61 \\
\hline & $v_{\text {eq(3rd })}[\%]$ & 8.14 & 9.33 & 13.5 \\
\hline \multirow[t]{2}{*}{$4 \cdot V_{\mathrm{y}}$} & $v_{\mathrm{eq}(1 \mathrm{st})}[\%]$ & 15.16 & 14.03 & 15.59 \\
\hline & $v_{\text {eq(3rd })}[\%]$ & 8.91 & 9.27 & 11.93 \\
\hline \multirow[t]{2}{*}{$6 \cdot V_{\mathrm{y}}$} & $v_{\text {eq(1st })}[\%]$ & 16.63 & 16.38 & 15.03 \\
\hline & $v_{\text {eq(3rd) }}[\%]$ & 9.33 & 8.84 & 10.87 \\
\hline \multirow[t]{2}{*}{$8 \cdot V_{\mathrm{y}}$} & $v_{\text {eq(1st })}[\%]$ & 31.89 & 12.64 & 14.04 \\
\hline & $v_{\text {eq(3rd) }}[\%]$ & 39.60 & 8.26 & 10.91 \\
\hline
\end{tabular}


cycle at $4 \cdot V_{\mathrm{y}}$ and at $6 \cdot V_{\mathrm{y}}$, respectively. However, it should be noticed that a much higher global cumulated energy dissipated is attained with the HTF-2 specimen, leading to significant advantages in case of a seismic event.

\section{CONCLUSIONS}

A hybrid timber-frame wall system is presented, in which the beams and studs are made of CLT instead of solid timber. Thanks to this hybrid approach, the mechanical behaviour of the wall is similar to a traditional LTF wall system while the energy dissipation is enhanced. Furthermore, this system permits to adopt some innovative connections with high mechanical properties. As a result, failure mechanisms either due to an eccentricity between the wall and the connection or to an intersection of the sheathing-panel between the anchoring device and the outer stud are prevented. Preliminary cyclic shear tests are carried out in the framework of the TRE3 research project on two configurations of interest, assembled by considering different layouts of the load-bearing elements.

Future developments of this study will investigate more in detail the structural behaviour of this hybrid wall system and will focus on the development of simplified design procedures to be used by practitioners. Moreover, analyses will take into account the effect of the vertical load applied on top of the wall, exploring the potentials of this new system for the erection of multi-storey structures in seismic-prone areas.

\section{ACKNOWLEDGEMENTS}

The experimental results presented in the paper were obtained in the framework of the TRE3 research project, funded by the Fondazione CARITRO - Cassa di Risparmio di Trento e Rovereto (Trento, Italy). The industrial partners X-Lam Dolomiti (Castel Ivano, Italy) and Rothoblaas (Cortaccia, Italy) are gratefully acknowledged for providing the materials used in the tests. Mario Pinna and Diego Magnago are gratefully acknowledged for preparation and running all the tests. Further acknowledgements are extended to Dr. Tiziano Sartori, who provided some useful remark on typical light-timber frame wall systems.

\section{REFERENCES}

[1] Filiatrault, A., Christovasilis, I.P., Wanitkorkul, A. \& Van de Lindt, J.W., Experimental seismic response of a full-scale light-frame wood building. Journal of Structural Engineering, 136(3), pp. 246-254, 2010. https://doi.org/10.1061/(ASCE)ST.1943-541X.0000112

[2] Van de Lindt, J.W., Pei, S., Pryor, S.E., Shimizu, H. \& Isoda, H., Experimental seismic response of a full-scale six-story light-frame wood building. Journal of Structural Engineering, 136(10), pp. 1262-1272, 2010. https://doi.org/10.1061/(ASCE)ST.1943-541X.0000222

[3] Ceccotti, A., Sandhaas, C., Okabe, M., Yasumura, M., Minowa, C. \& Kawai, N., SOFIE project - 3D shaking table test on a seven-storey full-scale cross-laminated building. Earthquake Engineering \& Structural Dynamics, 42(13), pp. 2003-2021, 2013. https://doi.org/10.1002/eqe.2309

[4] Seim, W. \& Vogt, T., Experimentelle und rechnerische Untersuchungen zur praxisgerechten Verankerung von Holzrahmenwänden. International Wood Construction Conference (Holzbau-Forum), Garmisch-Partenkirchen, Germany, 2013. 
[5] Seim, W., Hummel, J. \& Vogt, T., Earthquake design of timber structures: remarks on force-based design procedures for different wall systems. Engineering Structures, 76, pp. 124-137, 2014.

https://doi.org/10.1016/j.engstruct.2014.06.037

[6] Gavric, I., Fragiacomo, M. \& Ceccotti, A., Cyclic behavior of CLT wall systems: Experimental tests and analytical prediction models. Journal of Structural Engineering, 141(11), 04015034(1-14), 2015.

https://doi.org/10.1061/(ASCE)ST.1943-541X.0001246

[7] Flatscher, G., Bratulic, K. \& Schickhofer, G., Experimental tests on cross-laminated timber joints and walls. Proceedings of the ICE - Structures and Buildings, 168(11), pp. 868-877, 2015.

https://doi.org/10.1680/stbu.13.00085

[8] Flatscher, G. \& Schickhofer, G., Shaking-table test of a cross-laminated timber structure. Proceedings of the ICE - Structures and Buildings, 168(11), pp. 878-888, 2015. https://doi.org/10.1680/stbu.13.00086

[9] Grossi, P., Sartori, T. \& Tomasi, R., Tests on timber frame walls under in-plane forces: part 1. Proceedings of the ICE - Structures and Buildings, 168(11), pp. 826-839, 2015. https://doi.org/10.1680/stbu.13.00107

[10] Grossi, P., Sartori, T. \& Tomasi, R., Tests on timber frame walls under in-plane forces: part 2. Proceedings of the ICE - Structures and Buildings, 168(11), pp. 840-852, 2015. https://doi.org/10.1680/stbu.13.00108

[11] Tomasi, R., Casagrande, D., Grossi, P. \& Sartori, T., Shaking table tests on a three-storey timber building. Proceedings of the ICE - Structures and Buildings, 168(11), pp. 853-867, 2015.

https://doi.org/10.1680/jstbu.14.00026

[12] Casagrande, D., Grossi, P. \& Tomasi, R., Shake table tests on a full-scale timber-frame building with gypsum fibre boards. European Journal of Wood and Wood Products, 74(3), 425-442, 2016.

https://doi.org/10.1007/s00107-016-1013-6

[13] Popovski, M. \& Gavric, I., Performance of a 2-story CLT house subjected to lateral loads. Journal of Structural Engineering, 142(4), E4015006(1-12), 2016.

https://doi.org/10.1061/(ASCE)ST.1943-541X.0001315

[14] Yasumura, M., Kobayashi, K., Okabe, M., Miyake, T. \& Matsumoto, K., Full-scale tests and numerical analysis of low-rise CLT structures under lateral loading. Journal of Structural Engineering, 142(4), E4015007(1-12), 2016. https://doi.org/10.1061/(ASCE)ST.1943-541X.0001348

[15] ETA-15/0632. X-RAD: Three-dimensional nailing plate. OIB-Austria, Vienna, Austria, 2015.

[16] EN 1995-1-1:2004/A2. Eurocode 5: Design of timber structures. Part 1-1: General. Common rules and rules for buildings. CEN, Brussels, Belgium, 2014.

[17] Polastri, A., Brandner, R. \& Casagrande, D., Experimental analysis of a new connection system for CLT structures. Structures and Architecture: Concepts, Applications and Challenges, pp. 119-127, 2016.

https://doi.org/10.1201/b20891-14

[18] Polastri, A., Giongo, I. \& Piazza, M., An innovative connection system for CLT structures. Structural Engineering International, 2017. (Accepted, in press). 
[19] Casagrande, D., Sartori, T. \& Tomasi, R., Capacity design approach for multi-storey timber-frame buildings. INTER 2014 Meeting, Bath, United Kingdom (Paper 47-15-3), 2014.

[20] Follesa, M., Fragiacomo, M., Vassallo, D., Piazza, M., Tomasi, R., Rossi, S. \& Casagrande, D., A proposal for a new background document of Chapter 8 of Eurocode 8. INTER 2015 Meeting, Šibenik, Croatia (Paper 48-7-3), 2015.

[21] Casagrande, D., Rossi, S., Tomasi, R. \& Mischi, G., A predictive analytical model for the elasto-plastic behaviour of a light timber-frame shear-wall. Construction and Building Materials, 102, pp. 1113-1126, 2016.

https://doi.org/10.1016/j.conbuildmat.2015.06.025

[22] Presidenza del Consiglio dei Ministri - Dipartimento della Protezione Civile: Linee guida per l'individuazione delle aree di ricovero per strutture prefabbricate di protezione civile. Direttiva del Presidente del Consiglio dei Ministri (Gazzetta Ufficiale n. 44 del 23 febbraio 2005).

[23] Presidenza del Consiglio dei Ministri - Dipartimento della Protezione Civile: Manuale tecnico per l'allestimento delle aree di ricovero per strutture prefabbricate di protezione civile. Approvato con Decreto del Capo del Dipartimento della Protezione Civile (n. 1243 del 24 marzo 2005).

[24] ETA-12/0347, European Technical Assessment. Cross Laminated Timber (CLT) - Solid wood slab elements to be used as structural elements in buildings. OIB-Austria, Vienna, Austria, 2013.

[25] EN 12512:2001/A1, Timber structures. Test methods. Cyclic testing of joints made with mechanical fasteners. CEN, Brussels, Belgium, 2005.

[26] Izzi, M., Flatscher, G., Fragiacomo, M. \& Schickhofer, G., Experimental investigations and design provisions of steel-to-timber joints with annular-ringed shank nails for CrossLaminated Timber structures. Construction and Building Materials, 122, pp. 446-457, 2016.

https://doi.org/10.1016/j.conbuildmat.2016.06.072 